\title{
CINEMA AULA DE QUEM FOI QUE DISSE SOBRE A VIDA E O VIVER
}

\section{CINEMA AS A CLASSROOM IN THE MOVIE "WHO SAYS ABOUT THE LIFE AND THE LIVING"}

\author{
Edson Pereira da Silva ${ }^{3}$ \\ Luiz Antonio Botelho \\ Andrade $^{4}$
}

\begin{abstract}
Resumo
Este ensaio é uma análise fílmica de "Quem foi que disse: sobre a vida e o viver", primeiro de uma série de filmes do diretor Luiz Antônio Botelho Andrade. Para tanto é estabelecida a categoria de análise "cinema aula", a qual define o cinema do diretor como uma experiência de prática-teórica de construção-reconstrução-celebração do objeto de conhecimento no fazer cinema. Assim, o filme é compreendido na sua ontologia (é uma investigação de um tema de interesse), epistemologia (trabalha os elementos do problema para que eles exponham o que guardam) e pedagogia (constitui uma experiência coletiva de construção-reconstrução-celebração do conhecimento).
\end{abstract}

Palavras-chave: Gêneros cinematográficos. Cinema aula. Epistemologia.

\begin{abstract}
This essay is an analysis of "Quem foi que disse: sobre a vida e o viver", first in a series of films by director Luiz Antonio Botelho Andrade. The analysis was performed using the category here called "cinema aula" which defines the director's cinema as an experience of theoretical-practice of construction-reconstruction-celebration of the object of knowledge in making cinema. Thus, the film can be understood in its ontology (it is an investigation of a topic of interest), epistemology (it works the elements of the problem in order to free what is kept) and pedagogy (it constitutes a collective experience of constructionreconstruction-celebration of knowledge).
\end{abstract}

Keywords: Cinematographic genres. "Cinema aula". Epistemology.

\footnotetext{
${ }^{3}$ Possui bacharelado em Biologia Marinha pela Universidade Federal do Rio de Janeiro (1988), mestrado em Genética pela Universidade Federal do Rio de Janeiro (1991), doutorado em Genética pela University of WalesSwansea (1998) e pós-doutorado em Genética Molecular pela University of Swansea. Atualmente é professor adjunto da Universidade Federal Fluminense. Tem experiência na área de Genética, com ênfase em Genética de Populações de Organismos Marinhos, atuando principalmente nos seguintes temas: genética molecular, conservação, bioinvasão, teoria evolutiva, epistemologia e ensino. Email:labandrade@gmail.com .ORCID:0000-0003-2784-6260.

4 Programa de Pós-graduação em Diversidade e Inclusão da UFF, membro do Observatório Internacional de Inclusão, Interculturalidade e Inovação Pedagógica (OIIIIPE). Email: labandrade@gmail.com .ORCID:00000003-3925-2953.
} 


\section{RevistAleph}

\section{Introdução}

O filme "Quem foi que disse: Sobre a vida e o viver" (ANDRADE, 2008) é o primeiro de uma série de filmes que se definem como "educativos" (vide https://vimeo.com/28168576 ou https://labaciencias.com). Segundo o diretor, um dos autores deste artigo, o filme se utiliza de "formas narrativas" da ficção e do documentário. Neste sentido, utilizando-se do instrumento de classificação dos gêneros cinematográficos, poder-se-ia dizer, talvez, de uma forma ainda melhor, uma "Docuficção". Ou seja, um híbrido entre gêneros. O termo surgiu no início do século XXI e é fortemente apoiado na noção de híbrido (natural versus cultural) tão caro às teorias pós-modernas (LATOUR, 1994). Quem foi que disse: Sobre a vida e o viver seria, assim, um documentário "educativo" fascinado e/ou informado por elementos ficcionais.

Em princípio, a temática sobre a qual o filme se desenvolve é o conceito biológico de vida, mas envolve também uma discussão sobre a linguagem. Assim, segundo Humberto Maturana (1928-presente), teórico caro ao diretor, a linguagem é uma maneira dos indivíduos fluírem em interações recorrentes por meio de coordenações de coordenações condutuais consensuais (MATURANA, 1997). Destarte, a linguagem não tem lugar no corpo, mas no espaço de coordenações recorrentes e consensuais de conduta. Palavras são palavras apenas quando participam como elementos consensuais e recursivos das coordenações de conduta que constituem a linguagem. Neste sentido, a linguagem funda a conversa (cum-com o outro; versare- dar voltas) que se desdobra, como consequência, em comunicação. Ou seja, ao se dar voltas com o outro, coordena-se de forma recursiva e consensual no prazer (emoção) de estarem juntos ao atuarem no mundo (história) e não por uma necessidade teleológica de comunicabilidade.

Freire (2006, p. 85) problematiza e questiona até que ponto a linguagem cinematográfica pode ser utilizada para, esquecendo os argumentos, levar prazer ao espectador. Nesse contexto, o referido autor cita Jean Rouch (produtor de documentários de caráter antropológico) que afirmava que "todo filme deveria ter o rigor científico, mas ser também um poema".

Nesse ensaio, articulando o cinema com a temática do dossiê da RevistAleph Diálogo entre a Universidade e a Sociedade - as categorias de cinema educativo, híbridos (documentário, ficção, docuficção) e narrativa serão tensionadas em relação a uma análise 


\section{RevistAleph}

fílmica que privilegia a ideia do que será denominado aqui de "Cinema Aula". Ao se definir assim - Cinema Aula - não se está tentando expandir as já numerosas classificações dos gêneros cinematográficos que, acredita-se tratar:

de uma redução da classificação ao absurdo. Mas é, ao seu modo, as ruínas desse tipo de empirismo, representando a combinação de pelo menos três tipos de classificação: pela forma literária, pelo assunto e pelo público visado (esta última um tipo de evolução, em termos de setores especializados do mercado), sem falarmos das classificações que são combinações desses tipos, ou que representam tentativas desesperadas e posteriores de incluir um tipo misto, mas popular (WILLIAMS, 1979, p. 181).

Destarte, o objetivo desta categoria de análise - Cinema Aula - é valorizar os elementos criativos e inovadores da experiência de fazer cinema no âmbito da Universidade. Aproveita-se, assim, as páginas da RevistAleph para discutir um dos filmes do diretor Luiz Andrade produzido no âmbito da Universidade Federal Fluminense (UFF) e, também, dos aportes teóricos sobre cinema, produzidos na disciplina optativa (Cinema Ciência Ensino), oferecida pelo Prof. Edson Pereira da Silva, no Instituto de Biologia da UFF.

\section{UM FILME EDUCATIVO?}

A primeira categoria utilizada para enquadrar o filme é a de que ele se trata de um "filme educativo". Cabe se perguntar o que isso vem a ser. Todo cinema é prenhe de valores, crenças, visões de mundo e fatos históricos (DUARTE, 2002). Todo cinema representa um encontro com a alteridade (BERGALA, 2008). Nesse sentido, aquilo que há de mais pedagógico no cinema, para o desespero dos censores de plantão, não é a sua suposta mensagem, mas a sua linguagem. Eisenstein sabia muito bem disso.

Sergei Eisenstein (1898-1948), o diretor soviético do período revolucionário, deixou claro, na sua teoria da montagem, que o cinema não pode estar submetido à reprodução naturalista do mundo sensível, mas deve articular os planos de modo a ultrapassar a representação dos fatos e as aparências do mundo visível, reconstruindo a realidade sob uma perspectiva crítica e, portanto, empenhada na transformação da realidade. Por natureza o cinema é, portanto, uma epistemologia e uma pedagogia que nada se relaciona às unidades narrativas (suas sequências e mensagens) mas, sobretudo, às suas unidades poéticas (os planos e sua conotação). 


\section{RevistAleph}

Reduzir um filme a categoria de "educativo" é estar preocupado com o "perigo ideológico" que é a arma dos ressentidos e despreparados. O verdadeiro perigo é o estabelecimento do império da mediocridade e da nulidade artística. Como definiriam Adorno (1903-1969) e Horkheimer (1895-1973), deve-se lutar contra a produção cinematográfica de bens culturais padronizados que objetivam criar a docilidade e passividade das pessoas pela repetição acrítica de clichês e chavões. (ADORNO; HORKHEIMER, 1969).

\section{UMA DOCFICCÃO?}

Como defende a História Cultural, qualquer filme tem um teor documentarista (AVELINO; FLÓRIO, 2013). De forma especular, todo documentário é uma produção artística, o que, por definição, significa um trabalho de seleção e reconstrução da realidade seguindo determinados procedimentos. Um documentário não é a realidade "como ela é", mas é a realidade segundo um determinado referencial. Não há nada de errado nisso. 0 erro está ao se ignorar ou, o que é muito mais grave, esconder esse fato básico com uma pretensa objetividade ou realismo ingênuo. Nesses tempos de fakenews, pós-verdades e guerras de narrativas, afirmações como as que foram feitas podem parecer um endosso do relativismo das teorias pós-modernas. Contudo, é bem ao contrário disso, posto que o que está se defendendo é que não existe neutralidade no cinema, nem na ciência, nem na pedagogia.

Ou seja, no conhecimento de uma maneira geral. Mas é possível identificar claramente o referencial ao qual cada um deles está submetido. Não é uma "guerra de narrativas", mas uma tensão entre contrários bem definidos. Não é um mundo sem verdade, mas um mundo em que a verdade é o produto de um trabalho teórico com responsabilidades de classe bem definidas. É essa dialética que deve ser reconhecida contra o fundo caótico das ideologias que propalam o fim da história em plena história de crise do capitalismo.

Nesse sentido, os gêneros cinematográficos se constituem numa redução do fenômeno cinema e sua experiência. Jean-Luc Godard (1930-presente) já disse, em outro lugar, que "todo filme é um documentário dos seus atores". Nada mais claro e mais brilhante na definição dessa dialética para além dos gêneros cinematográficos e seus 


\section{RevistAleph}

híbridos. Não há híbridos posto que o cinema é uma unidade na diversidade e uma síntese de múltiplas determinações (MARX, 1858).

\section{CINEMA NARRATIVO?}

Como já foi explicitado, o cinema possui unidades narrativas que são as sequências. Algumas teorias do cinema privilegiam essas unidades e, dessa forma, definem os filmes pelas histórias que contam e pelas mensagens que veiculam. Nesse caso, a leitura ideológica dos filmes é direta. Essa forma de ver o cinema o identifica com a prosa, que se caracteriza por manter uma relação de descrição, comentário e ilustração da realidade.

Como também já foi dito, a unidade mínima dos filmes são os planos, que se definem pelos atos de explicitação: Ação! Corta! Uma característica interessante dessas unidades é que elas não são unidades narrativas (não tem significado em si mesmas), mas unidades significantes (vazias de significado) que só passam a ter sentido quando postas em relação umas com as outras, na montagem. Nessa perspectiva, o cinema se identifica muito mais com a poesia do que com a prosa, ou seja, com a sua compreensão. Neste sentido, o cinema lida com as experiências que ele próprio suscita.

O que Sergei Eisenstein, como criador, e Adorno e Horkheimer, como teóricos, nos apontam é para essa dimensão fundamental do cinema que é a sua linguagem. É na linguagem que o cinema opera sua ação racional e poética sobre a realidade e, dessa forma, executa uma verdadeira perscrutação do real, interrogando-o (epistemologia) e forjando-o (pedagogia) num trabalho ativo de objetivo claro de transformação do mundo dado em um mundo "projetado". Do mesmo modo, é na linguagem que a ideologia melhor exerce o seu poder de sujeição das pessoas, ao impor a elas uma repetição incessante de clichês que obliteram o senso crítico e convencem da impossibilidade de mudança, esvaziando a vontade de organização e de luta.

Nada do que se está dizendo aqui é novo e já foi bradado por Caetano Veloso (1942-presente) contra a direita e a esquerda irmanadas na burrice:

Mas é isso que é a juventude que diz que quer tomar o poder? Vocês têm coragem de aplaudir, este ano, uma música, um tipo de música que vocês não teriam coragem de aplaudir no ano passado!...Vocês não estão entendendo nada, nada, nada, absolutamente nada...Vocês estão por fora!... Mas que juventude é essa? Que juventude é essa? Vocês jamais 
conterão ninguém. Vocês são iguais sabem a quem?.... Àqueles que foram na Roda Viva e espancaram os atores!... Mas eu e Gil já abrimos o caminho. $\mathrm{O}$ que é que vocês querem? Eu vim aqui para acabar com isso! Eu quero dizer ao júri: me desclassifique. Eu não tenho nada a ver com isso. Nada a ver com isso.... Não fingimos aqui que desconhecemos o que seja festival, não.... Nós, eu e ele, tivemos coragem de entrar em todas as estruturas e sair de todas. E vocês? Se vocês forem... se vocês, em política, forem como são em estética, estamos feitos! O júri é muito simpático, mas é incompetente (Transcrição do áudio do discurso de Caetano Veloso "É proibido proibir" no III Festival Internacional da Canção-Fase Nacional, TV Globo, 15/09/1968).

Nesta perspectiva, a dicotomia forma-conteúdo é falsa, e não há revolução de conteúdo se a forma for reacionária. Forma reacionária é conteúdo reacionário. Já a subversão da forma não permite o conteúdo reacionário, embora possa ser vazia e descambar para o formalismo inócuo e niilista.

\section{CINEMA AULA}

O filme Quem foi que disse: Sobre a vida e o viver pode ser dividido, provisoriamente, em três partes. Na primeira, que pode ser chamada de ficção, uma pequena fábula sobre a pré-história é mostrada para ressaltar a importância da linguagem como criadora de distinções e a pergunta que anima o filme (o que é vida?). Na segunda, de caráter mais documental, são apresentadas cenas do mundo acadêmico (sala de aula, encontros científicos nacionais e internacionais) e entrevistas com especialistas, alunos e pessoas comuns que discutem o conceito biológico de vida. Neste particular, o diretor privilegia o conceito de autopoiesis (do grego auto-próprio; poiesis- criação) proposto pelos neurobiólogos chilenos Humberto Maturana e Francisco Varela (1946-2001). A terceira e última parte, todas (ou quase todas) as personagens do filme aparecem em cenas de um show de Daniel Gonzaga (1975-presente), filho do cantor e compositor Gonzaguinha (19451991), exatamente no momento da execução da canção O que é? O que é? (Gonzaguinha, 1982).

Ainda de interesse para o argumento que será defendido é a caracterização precária dos tempos, especialmente no que diz respeito à suposta pré-história retratada no filme. Homens se apresentam escanhoados e é quase possível sentir o cheiro de xampu que emana dos cabelos das mulheres. As roupas dos nossos antepassados pré-colombianos são também muito bem talhadas, denotando em nada o uso diário e cotidiano de vestes que 


\section{RevistAleph}

deveriam ser, além de precárias, rotas. Essas características poderiam ser tomadas como toscas ou como defeitos insanáveis do filme, não fosse ele um exemplo primoroso de um cinema aula.

Não há híbridos posto que o cinema é uma unidade na diversidade e uma síntese de múltiplas determinações $O$ que está sendo chamado aqui de cinema aula é a construção de uma experiência de prática teórica que envolve a pesquisa ativa (participação em encontros científicos, por exemplo), que leva a reconstrução do objeto na experiência (a encenação de pré-história, por exemplo) e sua celebração coletiva (a participação final em um show de MPB, por exemplo). O filme não nega sua ontologia, é uma investigação de um tema de interesse. O filme não nega sua epistemologia, é preciso trabalhar os elementos do problema para que eles exponham o que guardam. O filme não nega sua pedagogia, ele envolve e irmana a todos nessa experiência de construção-reconstrução-celebração do conhecimento. Nesse sentido, se trata sem dúvida de uma aula, na sua melhor definição: um tempo investido na aprendizagem. Não se trata de ensinar, mas de vivenciar/partilhar/experienciar o processo dialético de construção-reconstruçãocelebração do objeto de conhecimento (ANDRADE; SILVA, 2005; ANDRADE, 2018).

O que está sendo chamado aqui de cinema aula é cinema no seu compromisso total com a subversão do real. Como em "E la nave vá" de Fellini, 1983, no qual o mar é de papel celofane e a câmera faz um giro de 360 para nos mostrar do que se trata o cinema. Assim, também, Quem foi que disse: Sobre a vida e o viver nos mostra o tempo todo os seus agentes (no sentido de causa, origem, fonte, motivo). Eles cruzam as posições de alunos, professores, personagens, palestrantes, entrevistados, entrevistadores, sem o recurso artificial do hibridismo, mas na dialética daquilo que explicitou Godard: "todo filme é um documentário dos seus atores". Quem foi que disse: Sobre a vida e o viver é mais que um documentário dos seus atores, é também uma ficção dos sujeitos epistêmicos.

O que está sendo chamado de síntese dialética é essa junção de Apolo (razão) e Dionísio (emoção) nesta categoria cinema aula na qual Quem foi que disse: Sobre a vida e o viver realiza tão bem a construção-reconstrução-celebração do objeto chamado conhecimento. Isso mesmo! O filme é cinema, é aula, é aprendizagem. É polissêmico sem ser hibrido. Ensina sem ser educativo ou narrativo. É nesse sentido que a divisão provisória em três partes agora se extingue na síntese filme. É nesse sentido que a caracterização precária interessa mais pelo que mostra do que pelo que esconde. Contudo, uma questão 


\section{RevistAleph}

ainda pode perdurar depois desse breve ensaio, qual seja, a perspectiva do fazer cinemaaula como criação. Mas o que dizer da audiência? A audiência de Quem foi que disse: Sobre a vida e o viver se depara sempre com a grata satisfação de não estar diante de um filme feito para ensinar, mas com o qual o aprendizado será inevitável.

\section{Referências}

ADORNO, Theodor; HORKHEIMER, Max. Dialética do Esclarecimento: Fragmentos Filosóficos. Jorge Zahar Editor, Rio de Janeiro, 1969.

ANDRADE, Luiz Antonio Botelho. Quem foi que disse: Sobre a vida e o viver. Brasil, 2008. Disponível em https://vimeo.com/28168576.

ANDRADE, Luiz Antonio Botelho ; SILVA, Edson Pereira da. 0 conhecer e o conhecimento: comentários sobre o viver e o tempo. Ciências \& Cognição 4:35-41, 2005. Disponível em: http://www.cienciasecognicao.org/< Acesso em 10 de março de 2019.

ANDRADE, Luiz Antonio Botelho. Conhecimento é caminho: da metáfora ao mecanismo gerativo. Ciências e Cognição, v.23, p.117-128, 2018. Home page:

[http://www.cienciasecognicao.org/revista/index.php/cec/article/view/1462/pdf_107]

AVELINO, Yvone Dias ; FLÓRIO, Marcelo. História Cultural: O Cinema como Representação da Vida Cotidiana e suas Interpretações. Projeto História 48:18 p., 2013.

ARX, Karl. Grundrisse. Pelican Books, London, 1858.

BERGALA, Alain. A Hipótese-cinema: Pequeno Tratado de Transmissão do Cinema Dentro e Fora da Escola. Booklink/CINEAD-LISE-FE/UFRJ, Rio de Janeiro, 2008.

DUARTE, Rosália. Cinema e Educação. Autêntica, Belo Horizonte, 2002.

FELLINI, Federico. E la nave vá. Itália, 1983.

FREIRE, Marcius. Jean Rouch e a invenção do Outro no documentário. (Artigo desenvolvido a partir de comunicação apresentada no 13o. Visible Evidence -Encontro Internacional de Pesquisadores do Documentário, realizado na Cinemateca Brasileira, São Paulo, 2006. Disponível em: http://www.doc.ubi.pt/03/artigo_marcius_freire.pdf

GONZAGUINHA (Gonzaga Jr.), Luiz. O que é? O que é? In: LP/CD Caminhos do Coração. EMIOdeon, 1982.

LATOUR, Bruno. Jamais Fomos Modernos: Ensaio de Antropologia Simétrica. Editora 34, Rio de Janeiro, 1994.

MATURANA, Humberto. A Ontologia da realidade. Editora UFMG, Belo Horizonte, 1997.

WILLIAMS, Raymond. Marxismo e Literatura. Zahar Editores, Rio de Janeiro, 1979.

Data do envio: 03/06/2020

Data do aceite: 08/07/2020 